\title{
EVALUATION OF FINANCIAL PERFORMANCES IN TERMS OF SUB-SECTORS OF BASIC METAL INDUSTRY WITH AHP AND TOPSIS METHODS
}

\author{
DOI: 10.17261/Pressacademia.2018.858 \\ PAP- V.7-2018(11)-p.67-71
}

\section{Kemal Eyuboglu ${ }^{1}$, Yasar Bayraktar ${ }^{2}$}

${ }^{1}$ Karadeniz Technical University, Department of Business Administration, Trabzon, Turkey. keyuboglu@ktu.edu.tr, ORCID: 0000-0002-2108-9732

${ }^{2}$ Karadeniz Technical University, Department of Business Administration, Trabzon, Turkey. yasarbayraktar@ktu.edu.tr, ORCID: 0000-0002-6974-5292

To cite this document

Eyuboglu, K., Bayraktar, Y. (2018). Evaluation of financial performances in terms of sub-sectors of basic metal industry with AHP and TOPSIS methods. Pressacademia Procedia (PAP), V.7, p.67-71.

Permemant link to this document: $h$ ttp://doi.org/10.17261/Pressacademia.2018.858

Copyright: Published by PressAcademia and limited licenced re-use rights only.

\section{ABSTRACT}

Purpose- The purpose of the study discussed in this context is to analyze the financial performance of the sub-sectors in the basic metal industry for the period 2014-2016, considering the liquidity, financial structure, activity and profitability ratios.

Methodology- In the study, financial performances were analyzed with the AHP andTOPSIS methods by considering the ratios of liquidity, financial structure, activity and profitability of the sub-sectors in the basic metal industry. In this context, firstly weights of criteria are determined by using AHP method and then financial performance scores of sectors are calculated and ranked by TOPSIS method.

Findings- As a result of the analysis, it has been determined that the most successful sector for each year is the manufacturing sector of the other products obtained at the first processing of the steel. On the other hand, the manufacturing sector of main iron and steel products and ferro-alloys has been identified as the most unsuccessful sector.

Conclusion- The information provided in the light of these disclosures may help the potential investors, the sector representatives and the public managers who are considering investing in the basic metal industry sector.

Keywords: AHP, TOPSIS, financial performance, basic metal industry.

JEL Codes: C02, C44, M21

\section{ANA METAL SANAYi ALT SEKTÖRLERININ FINANSAL PERFORMANSLARININ AHP VE TOPSIS YÖNTEMLERI iLE DEĞERLENDIRILMESI}

ÖZET

Amaç- Çalışmanın amacı, 2014-2016 dönemi için ana metal sanayinde yer alan alt sektörlerin finansal performansları açısından likidite, finansal yapı, aktivite ve karlılık oranlarını dikkate alarak finansal performanslarını analiz etmektir.

Yöntem- Çalışmada, ana metal sanayinde yer alan alt sektörlerin likidite, finansal yapı, aktivite ve karlılığa ilişkin oranlar dikkate alınarak, Analitik Hiyerarşi Proses (AHP) ve TOPSIS (Technique for Order Preference by Similarity to Ideal Solution) yöntemleri ile finansal performansları analiz edilmiştir. Bu bağlamda öncelikle AHP yöntemi kullanılarak kriterlerin ağırlıkları belirlenmiş, ardından TOPSıS yöntemi ile sektörlerin finansal performans puanları hesaplanmış ve sıralanmıştır.

Bulgular- Yapılan analiz sonucunda her yıl için en başarılı sektörün çeliğin ilk işlenmesinde elde edilen diğer ürünlerin imalatı sektörü olduğu belirlenmiştir. Öte yandan ana demir ve çelik ürünleri ile ferro alaşımların imalatı sektörü ise en başarısız sektör olarak tespit edilmiştir. Sonuç- Bu açıklamalar ışığında ortaya konan bilgiler, ana metal sanayi sektörüne yatırım yapmayı düşünen potansiyel yatırımcılara, sektör temsilcilerine ve kamu yöneticilerine verecekleri kararlarda yardımcı olabilecektir.

Anahtar Kelimeler: AHP, TOPSIS, finansal performans, ana metal sanayi.

JEL Kodları: C02, C44, M21 


\section{GiRiş}

Türkiye'nin kalkınmasında önemli bir yer tutan sektörlerin başında ana metal sanayi sektörü gelmektedir. Bu sektör başta inşaat, kimya, enerji, otomotiv ve alt yapı yatırımları olmak üzere pek çok alana önemli girdiler sağlamaktadır (A\&T Bank, 2017: 2). Sanayinin en büyük sektörleri arasında yer alan bu sektörün varlığını sürdürebilmesi ve rekabet gücünü arttırabilmesi finansal performansına bağlıdır. Bu bağlamda ana metal sanayi işletmelerinin Türkiye ekonomisi açısından stratejik bir konumda bulunması sektör performansının sürekli olarak değerlendirilmesini işlevsel kılmaktadır. Finansal performans ölçümü, işletmelerin parasal politikaları ve faaliyet sonuçlarının ölçülmesi olarak tanımlanabilir. Finansal performans ile işletmelerin finansal pozisyonu, yatııımlarının verimliliği ve işletmenin risk derecesi belirlenebilmektedir. Ayrıca finansal performans, geçmişin sağlıklı bir biçimde değerlendirilmesi, gelecek için yatıım ve finansman kararlarının alınması ve kaynak kullanımı gibi konularda işletme yöneticilerine, sektöre ilgi duyan girişimcilere ve potansiyel yatırımcılara önemli bilgiler sağlamaktadır (Uygurtürk ve Korkmaz, 2012: 96). Yapılan açıklamalar ışı̆ı̆ında ele alınan bu çalışmada, Türkiye ekonomisi için stratejik bir konumda bulunan ana metal sanayi alt sektörlerinin finansal performanslarının karşılaştırıması amaçlanmışır. Literatürde söz konusu sektörlere yönelik çalışmaların az sayıda olması, çalışmanın literatüre katkııını ortaya koymaktadır. Bu bağlamda çalışmanın izleyen kısımlarında öncelikle imalat sektöründe performans değerlendirmesinin yapıldığı akademik yazın ele alınacak, ardından araştırma metodolojisi kapsamında kullanılan veri seti ile yöntem açıklanacaktır. Çalışmanın bulgular kısmında yapılan analizler sonucu elde edilen bilgiler sunulacaktır.

\section{LITERATÜR TARAMASI}

Akademik yazında çerçevesinde sektörlerin finansal performanslarının değerlendirildiği çalışmaların sayısı oldukça fazladır. Sektörler açııından karşılaştırma yapılan çalışmalarda ise; Ömürbek ve Mercan (2014), 2009-2011 dönemi için Türkiye'de imalat sanayi alt sektörlerinin finansal performanslarını karşılaştırmıştır. Çalışmada dokuz finansal orandan yararlanılmış ve performans ölçümünde TOPSIS ile ELECTRE yöntemleri kullanılmıştır. Sonuç olarak her iki yöntemde de kok kömürü ve rafine edilmiş petrol ürünleri imalatı sektörünün en iyi finansal performans gösteren sektör olduğu belirlenmiştir. Sungur ve Maden (2016), 2012 yılı için PROMETHEE yöntemi ile ỉBBS Düzey2 TR61 Bölgesi (Antalya, Isparta, Burdur) imalat sanayi sektörlerinin üstünlük sıralamasını yapmıştır. Çalışmada çalışan sayısı, maaş-ücretler, ciro ve brüt yatııım değişkenleri kullanılış ve imalat sanayi sektörleri sıralanmıştır. Çalışma sonucunda; ele alınan dört kriter açısından en yüksek net akım değerine sahip sektörlerin içecek, kimyasal, diğer ulaşım araçları, diğer mineral ürünler ve kağıt ürünleri sektörleri olduğu sonucuna ulaşılmıştır. Eyüboğlu (2016), 2009-2013 dönemi için TOPSIS yöntemi ile yedi gelişmekte ülke bankacılık sektörünün finansal performanslarını karşılaştırmıştır. Performans ölçümünde ise IMF Finansal Sağlamlık göstergeleri içerisinde yer alan on finansal oran kullanılmış ve sonuç olarak en başarılı bankacılık sektörüne sahip ülkelerin Türkiye ve G. Afrika olduğu tespit edilmiştir. Karadeniz vd. (2017), 2012-2014 dönemini dikkate alarak Türk imalat sektöründe yirmi bir alt sektörün finansal performansını Gri ilişkisel yöntemi ile analiz etmiştir. Otuz iki finansal oranının kullanıldığı çalışmada en başarııı performansa sahip üç alt sektörün sırasıyla; tütün ürünleri imalatı, kok kömürü ve rafine edilmiş petrol ürünlerinin imalatı ve içeceklerin imalatı sektörleri olduğu tespit edilmiştir.

\section{VERI SETI VE YÖNTEM}

Çalışmada Türk ana metal sanayi sektörünün 2014-2016 yılları için finansal performanslarının çok kriterli karar verme yöntemlerinden Analitik Hiyerarşi Proses (AHP) ve TOPSIS (Technique for Order Preference by Similarity to Ideal Solution) yöntemleri ile analiz edilmesi amaçlanmıştır. Yöntemlere ilişkin olarak yapılan açıklamalar ışığında çalışmada kullanılacak veriler elde edilmiştir. Türk ana metal sanayi sektörüne ilişkin finansal oranlar Türkiye Cumhuriyet Merkez Bankası (TCMB) Reel Sektör Verileri Müdürlüğü tarafından yayınlanmaktadır. Öte yandan ana metal sanayi alt sektörleri ise Avrupa Birliği İstatistik Ofisi (EUROSTAT) tarafından güncellenen ekonomik faaliyet sınıflandırılması NACE Revize 2 esas alınarak hazırlanmaktadır. Tablo 1'de NACE Revize 2 sınıflandırmasına göre oluşturulan Ana metal alt sektörleri gösterilmiştir.

Tablo 1: Ana Metal Sanayi Alt Sektörleri

\begin{tabular}{ll}
\hline NACE Revize 2 & Sektör Adı \\
\hline C241 & Ana Demir ve Çelik Ürünleri ile Ferro Alaşımların İmalatı \\
\hline C242 & Çelikten Tüpler, Borular, İçi Boş Profiller ve Benzeri Bağlantı Parç. İmalatı \\
\hline C243 & Çeliğin İlk İşlenmesinde Elde Edilen Diğer Ürünlerin İmalatı \\
\hline C244 & Değerli Ana Metaller ve Diğer Demir Dışı Metallerin İmalatı \\
\hline C245 & Metal Döküm Sanayii \\
\hline
\end{tabular}

İșletmelerin likidite, büyüme, karlılık gibi temel konularda güçlü ve zayıf taraflarının belirlenmesinde ya da başka işletmeler ile karşılaştırma yapılabilmesinde ise finansal oranlardan yararlanılmaktadır. Bu çalışmada likidite, faaliyet, finansal yapı, aktivite ve karlıık olmak üzere beş temel ve on dokuz alt finansal orandan faydalanılmıştır. Kriterlerin ağırlıklarının belirlenmesinde AHP, performans puanı hesaplaması ve sıralamasında ise TOPSIS yöntemleri kullanılmıştır.

\section{BULGULAR}

Çalışmanın bu bölümünde 2014-2016 dönemi için ana metal sanayi alt sektörlerinin finansal performansları hesaplanmış ve elde edilen bulgular yorumlanmıştır. 


\subsection{Finansal Rasyoların Ağırlıklarının Belirlenmesi}

Alt sektörlerin performanslarının değerlendirilmesinde her bir kriterin önem dereceleri AHP yöntemi kullanılarak belirlenmiştir. Bu aşamada ikili karşılaştırma matrisleri oluşturulurken bu konuda uzman akademisyen, bankacı ve sektör yöneticileri ile görüşülmüş, buna göre her bir kriterlerin önem dereceleri tespit edilmiş ve Tablo 2'de gösterilmiştir. Tutarlılık oranı (CR) ise 0.06 olarak hesaplanmıştır.

Tablo 2: Finansal Oranların Ağırlıkları

\begin{tabular}{|c|c|c|c|}
\hline Ana Oranlar & Ağırlıklar & Alt Oranlar & Ağırlıklar \\
\hline \multirow{4}{*}{ Likidite Oranları } & \multirow{4}{*}{0.261} & L1(Cari Oran) & 0,088 \\
\hline & & L2 (Likidite Oranı) & 0,076 \\
\hline & & L3 (Nakit Oranı) & 0,059 \\
\hline & & L4 (Stok Bağımlılık Oranı) & 0,038 \\
\hline \multirow{4}{*}{ Finansal Yapı Oranları } & \multirow{4}{*}{0.175} & F1(Yabancı Kaynaklar Toplamı/Aktif Toplamı) & 0,032 \\
\hline & & F2(Öz Kaynaklar/Aktif Toplamı) & 0,043 \\
\hline & & F3(Kısa Vadeli Yabancı Kaynaklar/Pasif Toplamı) & 0,058 \\
\hline & & F4 (Maddi Duran Varlıklar Net/Öz Kaynaklar) & 0,042 \\
\hline \multirow{5}{*}{ Aktivite Oranları } & \multirow{5}{*}{0.247} & A1(Stok Devir Hızı) & 0,058 \\
\hline & & A2(Alacak Devir Hızı) & 0,041 \\
\hline & & A3(Net Çalışma Sermayesi Devir Hızı) & 0,049 \\
\hline & & A4(Öz Kaynaklar Devir Hızı) & 0,044 \\
\hline & & A5 (Aktif Devir Hızı) & 0,055 \\
\hline \multirow{6}{*}{ Karlılık Oranları } & \multirow{6}{*}{0.317} & K1 (Net Kar/Öz Kaynaklar) & 0,066 \\
\hline & & K2 (Faiz Ve Vergi Öncesi Kar/Pasif Toplamı) & 0,039 \\
\hline & & K3 (Net Kar/Aktif Toplamı) & 0,042 \\
\hline & & K4 (Faaliyet Karı/Net Satışlar) & 0,046 \\
\hline & & K5 (Brüt Satış Karı / Net Satışlar) & 0,055 \\
\hline & & K6 (Net Kar /Net Satışlar) & 0,069 \\
\hline
\end{tabular}

\subsection{TOPSIS Yöntemi ile Finansal Performansların Değerlendirilmesi}

Tablo 3'te görüldüğü üzere karar matrisinin en üst satırında her bir kriterin önemini gösteren ağırlık değerleri bulunmaktadır. Ağırlık değerleri ikili karşılaştırmaları içeren anketlerin AHP yaklaşımı aracılığıyla değerlendirilmesi ile elde edilmiştir. Çalışmada 5 karar noktası (alt sektör) ve 19 değerlendirme kriteri (finansal oranlar) kullanılmıştır. TOPSIS yöntemi uygulamasında ilk aşamada (5x19) boyutlu karar matrisleri oluşturulmuştur.

Tablo 3: Karar Matrisleri

\begin{tabular}{|c|c|c|c|c|c|c|c|c|c|c|c|c|c|c|c|c|c|c|c|}
\hline \multicolumn{20}{|l|}{2014} \\
\hline & L1 & L2 & L3 & L4 & F1 & F2 & F3 & F4 & A1 & $A 2$ & A3 & A4 & A5 & K1 & K2 & K3 & K4 & K5 & K6 \\
\hline c241 & 127 & 66,5 & 20,7 & 157, & 64,1 & 35,9 & 45,7 & 104 & 5,3 & 9,7 & 3,1 & 4,4 & 1,3 & 4,8 & 5,4 & 0,1 & 4,8 & 8,2 & 1,4 \\
\hline c242 & 138, & 77,4 & 26,6 & 167 & 69,2 & 30,8 & 53,8 & 87,4 & 4,9 & 5,9 & 3,8 & 5,3 & 1,2 & 6,6 & 7,6 & 2,6 & 6,8 & 15,3 & 2,4 \\
\hline c243 & 153 & 99,7 & 39,4 & 222 & 67,7 & 32,3 & 49,4 & 103 & 11,7 & 7,4 & 1,6 & 6,2 & 1,5 & 14,3 & 9,0 & 4,2 & 6,3 & 11,7 & 2,7 \\
\hline c244 & 138 & 80,6 & 32,7 & 168 & 71,8 & 28,2 & 50,9 & 95,4 & 6,7 & 5,5 & 5,6 & 5,2 & 1,2 & 6,9 & 6,4 & 2,1 & 5,7 & 10,5 & 2,2 \\
\hline c245 & 126 & 76,9 & 16,5 & 181 & 66,7 & 33,3 & 44,1 & 111 & 6,5 & 6,6 & 0,6 & 3,5 & 1,1 & 15,7 & 6,8 & 3,6 & 7,3 & 17,0 & 3,3 \\
\hline \multicolumn{20}{|l|}{2015} \\
\hline & L1 & L2 & L3 & L4 & F1 & F2 & F3 & F4 & A1 & A2 & A3 & A4 & A5 & K1 & K2 & K3 & K4 & K5 & K6 \\
\hline c241 & 111, & 58,9 & 21,1 & 202 & 68,1 & 31,9 & 47,7 & 127, & 5,6 & 8,9 & 2,0 & 4,3 & 1,1 & 5,4 & 4,0 & 1,5 & 5,1 & 9,8 & 1,5 \\
\hline c242 & 134, & 76,9 & 25,9 & 199, & 67,4 & 32,6 & 51,4 & 95,8 & 4,8 & 4,7 & 2,1 & 5,1 & 1,1 & 9,2 & 9,3 & 2,4 & 6,9 & 14,5 & 2,0 \\
\hline c243 & 168 & 115 & 53,1 & 222 & 68,6 & 31,4 & 47,5 & 125 & 11,1 & 8,2 & 0,5 & 4,7 & 1,4 & 8,7 & 8,9 & 3,1 & 6,1 & 11,5 & 2,0 \\
\hline c244 & 144 & 88,6 & 29,4 & 199, & 72,2 & 27,8 & 50,0 & 76,4 & 6,7 & 5,7 & 7,2 & 5,4 & 1,2 & 7,8 & 6,4 & 2,2 & 6,4 & 11,7 & 1,3 \\
\hline c245 & 145 & 91,2 & 28,4 & 191, & 65,1 & 34,9 & 45,4 & 118 & 5,2 & 6,4 & 1,8 & 3,3 & 1,0 & 8,9 & 6,4 & 1,7 & 9,1 & 18,1 & 2,8 \\
\hline \multicolumn{20}{|l|}{2016} \\
\hline & L1 & L2 & L3 & L4 & F1 & F2 & F3 & F4 & A1 & A2 & A3 & A4 & A5 & K1 & K2 & K3 & K4 & K5 & K6 \\
\hline c241 & 135, & 75,5 & 26,4 & 196, & 68,6 & 31,4 & 47,8 & 131, & 5,5 & 8,5 & 4,4 & 4,1 & 1,0 & 0,8 & 6,1 & 0,8 & 6,2 & 11,3 & 0,5 \\
\hline c242 & 155, & 88,9 & 33,8 & 171 & 65,9 & 34,1 & 53,0 & 80,3 & 4,2 & 4,1 & 0,3 & 4,0 & 1,0 & 11,0 & 11,1 & 4,2 & 10,5 & 17,7 & 3,6 \\
\hline c243 & 161, & 104 & 45,7 & 225 & 66,6 & 33,4 & 50,6 & 88,3 & 9,2 & 7,8 & 1,9 & 5,5 & 1,3 & 13,3 & 8,4 & 3,5 & 8,5 & 13,7 & 4,2 \\
\hline c244 & 163 & 102 & 33,9 & 150 & 68,6 & 31,4 & 50,1 & 71,5 & 6,0 & 5,1 & 4,2 & 4,2 & 1,0 & 4,8 & 4,8 & 0,9 & 6,6 & 13,0 & 0,9 \\
\hline c245 & 116 & 71,7 & 23,3 & 223 & 68,9 & 31,1 & 48,1 & 128 & 5,0 & 6,5 & 1,0 & 2,9 & 0,9 & 4,2 & 6,3 & 1,3 & 7,2 & 17,1 & 0,6 \\
\hline
\end{tabular}

Karar matrisleri oluşturulduktan sonra formülü ve Tablo 4'te gösterilmiştir.

$$
r_{i j}=\frac{a_{i j}}{\sqrt{\sum_{k=1}^{m} a_{k j}^{2}}} \text { kullanılarak normalleştirilmiş karar matrisi elde edilmiş }
$$


Tablo 4: Normalleştirilmiş Karar Matrisleri

\begin{tabular}{|c|c|c|c|c|c|c|c|c|c|c|c|c|c|c|c|c|c|c|c|}
\hline \multicolumn{20}{|c|}{2014} \\
\hline & L1 & L2 & L3 & L4 & F1 & F2 & F3 & F4 & A1 & A2 & A3 & A4 & A5 & K1 & K2 & K3 & K4 & K5 & K6 \\
\hline c241 & 0,41 & 0,36 & 0,32 & 0,38 & 0,42 & 0,49 & 0,41 & 0,46 & 0,31 & 0,60 & 0,41 & 0,39 & 0,45 & 0,20 & 0,33 & 0,01 & 0,34 & 0,28 & 0,25 \\
\hline $\mathrm{c} 242$ & 0,45 & 0,42 & 0,41 & 0,41 & 0,45 & 0,42 & 0,49 & 0,38 & 0,29 & 0,36 & 0,49 & 0,47 & 0,41 & 0,27 & 0,47 & 0,40 & 0,48 & 0,52 & 0,43 \\
\hline c243 & 0,50 & 0,55 & 0,62 & 0,54 & 0,44 & 0,44 & 0,45 & 0,45 & 0,70 & 0,46 & 0,21 & 0,55 & 0,52 & 0,60 & 0,56 & 0,64 & 0,44 & 0,40 & 0,48 \\
\hline c244 & 0,45 & 0,44 & 0,51 & 0,41 & 0,47 & 0,39 & 0,46 & 0,42 & 0,40 & 0,34 & 0,73 & 0,46 & 0,43 & 0,28 & 0,40 & 0,32 & 0,41 & 0,36 & 0,39 \\
\hline c245 & 0,41 & 0,42 & 0,26 & 0,44 & 0,43 & 0,46 & 0,40 & 0,49 & 0,39 & 0,41 & 0,07 & 0,31 & 0,38 & 0,66 & 0,42 & 0,55 & 0,52 & 0,58 & 0,59 \\
\hline \multicolumn{20}{|l|}{2015} \\
\hline & L1 & L2 & L3 & L4 & F1 & F2 & F3 & F4 & A1 & A2 & A3 & A4 & A5 & K1 & K2 & K3 & K4 & K5 & K6 \\
\hline c241 & 0,35 & 0,29 & 0,28 & 0,44 & 0,44 & 0,44 & 0,44 & 0,51 & 0,35 & 0,57 & 0,24 & 0,41 & 0,42 & - & 0,24 & - & 0,33 & 0,32 & - \\
\hline c242 & 0,42 & 0,39 & 0,34 & 0,43 & 0,44 & 0,45 & 0,47 & 0,38 & 0,30 & 0,29 & 0,26 & 0,49 & 0,43 & 0,50 & 0,57 & 0,47 & 0,44 & 0,48 & 0,45 \\
\hline c243 & 0,53 & 0,58 & 0,70 & 0,48 & 0,44 & 0,44 & 0,43 & 0,50 & 0,70 & 0,53 & 0,06 & 0,46 & 0,53 & 0,47 & 0,54 & 0,61 & 0,39 & 0,38 & 0,45 \\
\hline c244 & 0,45 & 0,44 & 0,39 & 0,43 & 0,47 & 0,39 & 0,46 & 0,31 & 0,42 & 0,36 & 0,90 & 0,52 & 0,45 & 0,43 & 0,39 & 0,43 & 0,41 & 0,38 & 0,29 \\
\hline $\mathrm{c} 245$ & 0,45 & 0,46 & 0,37 & 0,42 & 0,42 & 0,49 & 0,41 & 0,47 & 0,32 & 0,40 & 0,23 & 0,32 & 0,37 & 0,49 & 0,39 & 0,33 & 0,59 & 0,60 & 0,61 \\
\hline \multicolumn{20}{|l|}{2016} \\
\hline & L1 & L2 & L3 & L4 & F1 & F2 & F3 & F4 & A1 & A2 & A3 & A4 & A5 & K1 & K2 & K3 & K4 & K5 & K6 \\
\hline c241 & 0,41 & 0,37 & 0,35 & 0,44 & 0,45 & 0,43 & 0,42 & 0,56 & 0,39 & 0,57 & 0,67 & 0,43 & 0,44 & 0,04 & 0,35 & 0,14 & 0,34 & 0,34 & - \\
\hline c242 & 0,47 & 0,44 & 0,45 & 0,39 & 0,43 & 0,47 & 0,47 & 0,34 & 0,30 & 0,27 & - & 0,42 & 0,43 & 0,59 & 0,64 & 0,72 & 0,59 & 0,53 & 0,63 \\
\hline c243 & 0,48 & 0,52 & 0,60 & 0,51 & 0,44 & 0,46 & 0,45 & 0,38 & 0,66 & 0,52 & - & 0,58 & 0,53 & 0,72 & 0,49 & 0,61 & 0,47 & 0,41 & 0,74 \\
\hline c244 & 0,49 & 0,51 & 0,45 & 0,34 & 0,45 & 0,43 & 0,44 & 0,31 & 0,43 & 0,34 & 0,65 & 0,44 & 0,41 & 0,26 & 0,27 & 0,15 & 0,37 & 0,39 & 0,15 \\
\hline c245 & 0,35 & 0,35 & 0,31 & 0,51 & 0,45 & 0,43 & 0,43 & 0,55 & 0,35 & 0,44 & 0,16 & 0,30 & 0,38 & 0,22 & 0,36 & 0,23 & 0,40 & 0,51 & - \\
\hline
\end{tabular}

Normalleştirilmiş değerler ağırlıklar ile çarpılarak ( $\mathrm{Vij}=\omega i j \mathrm{j}$ R Rij) ağırlıklı standart karar matrisi elde edilmiş ve Tablo $5^{\prime}$ de gösterilmiştir.

Tablo 5: Ağırlıklı Standart Karar Matrisleri

\begin{tabular}{|c|c|c|c|c|c|c|c|c|c|c|c|c|c|c|c|c|c|c|c|}
\hline \multicolumn{20}{|l|}{2014} \\
\hline & L1 & L2 & L3 & L4 & \begin{tabular}{|l|}
$F 1$ \\
\end{tabular} & F2 & F3 & \begin{tabular}{|l|} 
F4 \\
\end{tabular} & A1 & A2 & A3 & A4 & A5 & K1 & K2 & K3 & K4 & \begin{tabular}{|l|} 
K5 \\
\end{tabular} & \begin{tabular}{|l|} 
K6 \\
\end{tabular} \\
\hline c241 & 0,03 & 0,02 & 0,01 & 0,01 & 0,01 & 0,02 & 0,02 & 0,01 & 0,01 & 0,02 & 0,02 & 0,01 & 0,02 & 0,01 & 0,01 & 0,00 & 0,01 & 0,01 & 0,01 \\
\hline c242 & 0,04 & 0,03 & 0,02 & 0,01 & 0,01 & 0,01 & 0,02 & 0,01 & 0,01 & 0,01 & 0,02 & 0,02 & 0,02 & 0,01 & 0,01 & 0,01 & 0,02 & 0,02 & 0,03 \\
\hline c243 & 0,04 & 0,04 & 0,03 & 0,02 & 0,01 & 0,01 & 0,02 & \begin{tabular}{|l|}
0,01 \\
\end{tabular} & 0,04 & 0,01 & 0,01 & 0,02 & 0,02 & 0,04 & 0,02 & 0,02 & 0,02 & 0,02 & 0,03 \\
\hline c244 & 0,04 & 0,03 & 0,03 & 0,01 & 0,01 & 0,01 & 0,02 & 0,01 & 0,02 & 0,01 & 0,03 & 0,02 & 0,02 & 0,01 & 0,01 & 0,01 & 0,01 & 0,02 & 0,02 \\
\hline c245 & 0,03 & 0,03 & 0,01 & 0,01 & 0,01 & 0,02 & 0,02 & 0,02 & 0,02 & 0,01 & 0,00 & 0,01 & 0,02 & 0,04 & 0,01 & 0,02 & 0,02 & 0,03 & $\mid 0,04$ \\
\hline \multicolumn{20}{|l|}{2015} \\
\hline & L1 & $\mathrm{L} 2$ & L3 & L4 & F1 & F2 & F3 & F4 & A1 & A2 & A3 & A4 & A5 & K1 & K2 & K3 & K4 & K5 & K6 \\
\hline c241 & 0,03 & 0,02 & 0,01 & 0,01 & 0,01 & 0,01 & 0,02 & 0,02 & 0,02 & 0,02 & 0,01 & 0,01 & 0,02 & & 0,01 & - & 0,01 & 0,01 & - \\
\hline c242 & 0,03 & 0,03 & 0,02 & 0,01 & 0,01 & 0,02 & 0,02 & 0,01 & 0,01 & 0,01 & 0,01 & 0,02 & 0,02 & 0,03 & 0,02 & 0,02 & 0,02 & 0,02 & 0,03 \\
\hline c243 & 0,04 & 0,04 & 0,04 & 0,01 & 0,01 & 0,01 & 0,02 & 0,02 & 0,04 & 0,02 & 0,00 & 0,02 & 0,02 & 0,03 & 0,02 & 0,02 & 0,01 & 0,02 & 0,03 \\
\hline c244 & 0,04 & 0,03 & 0,02 & 0,01 & 0,01 & 0,01 & 0,02 & 0,01 & 0,02 & 0,01 & 0,04 & 0,02 & 0,02 & 0,02 & 0,01 & 0,01 & 0,01 & 0,02 & 0,02 \\
\hline c245 & 0,04 & 0,03 & 0,02 & 0,01 & 0,01 & 0,02 & 0,02 & 0,02 & 0,01 & 0,01 & 0,01 & 0,01 & 0,02 & 0,03 & 0,01 & 0,01 & 0,02 & 0,03 & 0,04 \\
\hline \multicolumn{20}{|l|}{2016} \\
\hline & L1 & L2 & L3 & L4 & F1 & F2 & F3 & F4 & A1 & A2 & A3 & A4 & A5 & K1 & K2 & K3 & K4 & K5 & \begin{tabular}{|l|}
$K 6$ \\
\end{tabular} \\
\hline c241 & 0,03 & 0,02 & 0,02 & 0,01 & 0,01 & 0,01 & 0,02 & 0,02 & 0,02 & 0,02 & 0,03 & 0,01 & 0,02 & 0,00 & 0,01 & 0,00 & 0,01 & 0,01 & - \\
\hline c242 & 0,04 & 0,03 & 0,02 & 0,01 & 0,01 & 0,02 & 0,02 & 0,01 & 0,01 & 0,01 & - & 0,01 & 0,02 & 0,04 & 0,02 & 0,03 & 0,02 & 0,02 & 0,04 \\
\hline c243 & 0,04 & 0,04 & 0,03 & 0,02 & 0,01 & 0,02 & 0,02 & 0,01 & 0,03 & 0,02 & - & 0,02 & 0,03 & 0,04 & 0,01 & 0,02 & 0,02 & 0,02 & 0,05 \\
\hline c244 & 0,04 & 0,03 & 0,02 & 0,01 & 0,01 & 0,01 & 0,02 & 0,01 & 0,02 & 0,01 & 0,03 & 0,02 & 0,02 & 0,01 & 0,01 & 0,00 & 0,01 & 0,02 & 0,01 \\
\hline c245 & 0,03 & 0,02 & 0,01 & 0,01 & 0,01 & 0,01 & 0,02 & 0,02 & 0,02 & 0,01 & 0,00 & 0,01 & 0,02 & 0,01 & 0,01 & 0,01 & 0,01 & 0,02 & - \\
\hline \multicolumn{20}{|c|}{$\begin{array}{l}\text { Sonrasında ideal }\left(A^{+}\right) \text {ve negatif ideal }\left(A^{-}\right) \text {çözümler oluşturulmuştur. } A^{+} \text {seti için } V \text { matrisinin her bir sütunundaki en büyük değer, } A^{-} \text {seti için } \\
V \text { matrisinin her bir sütunundaki en küçük değer seçilmiștir. Setler, kriterlerin amacına göre Tablo } 6^{\prime} \text { da gösterilmiştir. }\end{array}$} \\
\hline \multicolumn{20}{|c|}{ Tablo 6: İdeal ( $A^{+}$) ve Negatif İdeal ( $\left.A^{-}\right)$Çözümler } \\
\hline \multicolumn{20}{|l|}{2014} \\
\hline A* $^{*}$ & 0,04 & 0,04 & 0,03 & 0,01 & 0,01 & 0,02 & 0,02 & \begin{tabular}{|l|l|} 
\\
\end{tabular} & 0,04 & 0,02 & 0,03 & 0,02 & 0,02 & 0,04 & 0,02 & 0,02 & 0,02 & 0,03 & 0,04 \\
\hline$A^{-}$ & 0,03 & 0,02 & 0,01 & 0,02 & 0,01 & 0,01 & 0,02 & 0,02 & 0,01 & 0,01 & 0,00 & 0,01 & 0,02 & 0,01 & 0,01 & 0,00 & 0,01 & 0,01 & \begin{tabular}{|l|l}
0,01 \\
\end{tabular} \\
\hline \multicolumn{20}{|l|}{2015} \\
\hline$A^{*}$ & 0,04 & 0,04 & 0,04 & 0,01 & 0,01 & 0,02 & 0,02 & \begin{tabular}{|l|l|}
0,01 \\
\end{tabular} & 0,04 & 0,02 & 0,04 & 0,02 & 0,02 & 0,03 & 0,02 & 0,02 & 0,02 & 0,03 & 0,04 \\
\hline$A^{-}$ & 0,03 & 0,02 & 0,01 & 0,01 & 0,01 & 0,01 & 0,02 & 0,02 & 0,01 & 0,01 & 0,00 & 0,01 & 0,02 & - & 0,01 & - & 0,01 & 0,01 & $\left.\right|^{-}$ \\
\hline \multicolumn{20}{|l|}{2016} \\
\hline$A^{*}$ & 0,04 & 0,04 & 0,03 & 0,01 & 0,01 & 0,02 & 0,02 & 0,01 & 0,03 & 0,02 & 0,03 & 0,02 & 0,03 & 0,04 & 0,02 & 0,03 & 0,02 & 0,02 & 0,05 \\
\hline$A^{-}$ & 0,03 & 0,02 & 0,01 & 0,02 & 0,01 & 0,01 & 0,02 & 0,02 & 0,01 & 0,01 & - & 0,01 & 0,02 & 0,00 & 0,01 & 0,00 & 0,01 & 0,01 & - \\
\hline
\end{tabular}


Tablo 7'de ise 2014-2016 yılları arasında çalışmada yer alan metal ana sanayi alt sektörlerinin pozitif-ideal çözümden olan uzaklıkları ( $\mathrm{S}^{+}$), negatif-ideal çözümden olan uzaklıkları $\left(S_{i}^{-}\right)$, performans puanları ve sıralamaları gösterilmiştir.

Tablo 7: Yıllara göre Ana Metal Sanayi Alt Sektörlerinin Performans Puanları ve Sıralamaları

\begin{tabular}{|c|c|c|c|c|}
\hline \multicolumn{5}{|l|}{2014} \\
\hline Alt Sektör & S* & $S^{-}$ & (C) Puan & Siralama \\
\hline c241 & 0,063 & 0,023 & 0,382 & 5 \\
\hline c242 & 0,045 & 0,037 & 0,856 & 4 \\
\hline c243 & 0,030 & 0,058 & 1,956 & 1 \\
\hline c244 & 0,042 & 0,042 & 1,036 & 3 \\
\hline $\mathrm{c} 245$ & 0,047 & 0,050 & 1,094 & 2 \\
\hline \multicolumn{5}{|l|}{2015} \\
\hline Alt Sektör & S* & $\mathrm{S}^{-}$ & (C) Puan & Siralama \\
\hline c241 & 0,111 & 0,016 & 0,160 & 5 \\
\hline $\mathrm{c} 242$ & 0,052 & 0,087 & 1,751 & 4 \\
\hline c243 & 0,046 & 0,097 & 2,190 & 1 \\
\hline c244 & 0,041 & 0,086 & 2,170 & 2 \\
\hline $\mathrm{c} 245$ & 0,050 & 0,093 & 1,947 & 3 \\
\hline \multicolumn{5}{|l|}{2016} \\
\hline Alt Sektör & S* & $S^{-}$ & (C) Puan & Siralama \\
\hline c241 & 0,084 & 0,051 & 0,653 & 4 \\
\hline $\mathrm{c} 242$ & 0,047 & 0,074 & 1,667 & 2 \\
\hline $\mathrm{c} 243$ & 0,050 & 0,086 & 1,822 & 1 \\
\hline $\mathrm{c} 244$ & 0,063 & 0,058 & 0,980 & 3 \\
\hline $\mathrm{c} 245$ & 0,084 & 0,029 & 0,371 & 5 \\
\hline
\end{tabular}

\section{SONUC}

Ana metal sanayi sektörü, ülke ekonomisine istihdam oluşturması, yüksek sermaye gerektirmesi ve diğer sektörler için itici güç olması gibi nedenlerden ötürü Türkiye açısından stratejik öneme sahiptir. Sektörün ekonomik yönden güçlü olması hem kendi hem de ülke ekonomisi açısından önem arz etmektedir. Sektörün ekonomik yönden gücünün göstergesi finansal performansının ölçümü ve analiz edilmesidir. Bu bağlamda ele alınan bu çalışmada ana metal sanayi sektörü kapsamında bulunan beş alt sektörün 2014-2016 dönemi için finansal performanslarının analizi amaçlanmış ve alt sektörler karşılaştırılmıştır. Öncelikle finansal performansın ölçümünde kullanılacak finansal oranlar belirlenmiş, ardından AHP yöntemi ile finansal oranların önem dereceleri belirlenmiştir. Ardından TOPSIS yöntemi ile sektörlerin finansal performans puanları hesaplanmış ve sıralanmıştır. Yapılan analiz sonucunda her yıl için en başarılı sektörün çeliğin ilk işlenmesinde elde edilen diğer ürünlerin imalatı sektörü olduğu belirlenmiştir. Ana demir ve çelik ürünleri ile ferro alaşımların imalatı sektörü ise en başarısız sektör olarak tespit edilmiştir. Dolayısıyla çalışmadan elde edilen sonuçlar ana metal sanayi mevcut veya potansiyel yatırımcılarına, sektör temsilcilerine ve kamu yöneticilerine verecekleri kararlarda yardımcı olabilecektir. Öte yandan 2017 yılı itibariyle gerçekleşen kamu yatırımlarındaki artış ve Kredi Garanti Fonu katkısı ile ana metal sanayi sektöründeki gelişimin gelecek yıllarda devam edeceği düşünülmektedir. Bu bağlamda farklı sektörlerin finansal performansları karşılaştırılarak literatüre katkı sağlanabileceği gibi potansiyel yatırımcılara da aydınlatıcı bilgiler sunulabilir.

\section{KAYNAKLAR}

Eyüboğlu, K. (2016). Comparison financial performances of developing countries' banking sectors with TOPSIS method. Sosyal Bilimler Araştırmaları Dergisi, (14), 220-236.

https://www.atbank.com.tr/documents/ANA\%20METAL\%20SANAYI\%20SEKTORU_EYLUL\%202017.PDF., 12.03.2018.

Karadeniz, E., Koşan, L., Günay, F., Beyazgül, M. (2017). Türk imalat sektöründe finansal performansin gri ilişkisel analiz yöntemi ile incelenmesi: Türkiye Cumhuriyet Merkez Bankası imalat alt sektör bilançolarinda bir araştırma. Muhasebe ve Vergi Uygulamaları Dergisi (MUVU)/Journal of Accounting \& Taxation Studies (JATS), 10(2).

Ömürbek, N., Mercan, Y. (2014). İmalat alt sektörlerinin finansal performanslarinın TOPSIS ve ELECTRE yöntemleri ile değerlendirilmesi. Çankırı Karatekin Üniversitesi IiBF Dergisi, 4(1), 237-266.

Sungur, O., Maden, S. I. (2016). TR61 bölgesi (Antalya, Isparta, Burdur) imalat sanayi sektörlerinin PROMETHEE yöntemi ile sıralanması. Ege Akademik Bakış, 16(4), 641.

Türkiye Cumhuriyet Merkez Bankası, http://www3.tcmb.gov.tr/sektor/2017/menu.php, 24.02.2018

Uygurtürk, H., Korkmaz, T. (2012). Finansal performansın TOPSIS çok kriterli karar verme yöntemi ile belirlenmesi: ana metal sanayi işletmeleri üzerine bir uygulama. Eskişehir Osmangazi Üniversitesi İktisadi ve İdari Bilimler Dergisi, 7(2), 95-115. 